\title{
Sintesis dan Karakterisasi Sifat Optik Eosin Y @ Metal- Organic Framework Zirkonium Naftalendikarboksilat
}

\section{Synthesis and Characterization of Optical Properties of EosinY @ Zirconium Naphtalenedicarboxylic Metal-Organic Framework}

\author{
R. F. Kesuma ${ }^{1 *}$, L. Yuliati ${ }^{2}$ dan T. H. P. Brotosudarmo ${ }^{2}$ \\ ${ }^{1}$ Program Studi Kimia, Fakultas Sains dan Teknologi, Universitas Ma Chung, \\ Villa Puncak Tidar N-01, Malang 65151, Jawa Timur, Indonesia \\ ${ }^{2} \mathrm{Ma}$ Chung Research Center for Photosynthetic Pigments, Universitas Ma Chung, \\ Villa Puncak Tidar N-01, Malang 65151, Jawa Timur, Indonesia
}

\begin{abstract}
Eosin Y has been successfully assembled with Zirconium Naphtalenedicarboxylic Metal-Organic Framework (Zr-NDC MOF) by adding Eosin Y in ethanol solution $(0.034 \mathrm{ml}$, $\left.10^{-4} \mathrm{M}\right)$ onto the Zr-NDC MOF (0.3 g). Powder X-ray diffraction (PXRD) measurement was carried out to confirm the formation of Zr-NDC MOF with characteristic peaks at $2 \theta$ of 6.47 and 7.45 degrees. UV-vis diffuse reflectance spectra were obtained by UV-vis spectrophotometer. Zr-NDC MOF gave absorption at $274 \mathrm{~nm}$ corresponding to band gap energy of $4.32 \mathrm{eV}$, while Eosin Y showed absorption at $524 \mathrm{~nm}$. On the other hand, Eosin Y@Zr-NDC MOF exhibited absorption peaks at 300, 357, and $524 \mathrm{~nm}$, which were correlated with band gap energy of $3.65,3.15$, and $2.19 \mathrm{eV}$, respectively.
\end{abstract}

Keywords : Metal-organic framework Zr-NDC, Eosin Y, band gap energy

\begin{abstract}
ABSTRAK
Eosin Y telah berhasil diembankan pada Metal-Organic Framework Zirkonium Naftalendikarboksilat (MOF Zr-NDC) dengan cara menambahkan Eosin Y dalam pelarut etanol $\left(0,034 \mathrm{ml}, 10^{-4} \mathrm{M}\right)$ pada MOF Zr-NDC (0,3 g). Pengukuran Powder X-Ray Diffraction (PXRD) dilakukan untuk mengkonfirmasi pembentukan MOF Zr-NDC dengan puncak khas pada $2 \theta$ di 6.47 dan 7.45. Spektra UV-vis Diffuse Reflectance Spectra diperoleh dengan menggunakan spektrofotometer UV-vis. MOF Zr-NDC memberikan serapan pada $274 \mathrm{~nm}$ yang berhubungan dengan energi celah sebesar $4.32 \mathrm{eV}$, sedangkan Eosin Y menunjukkan serapan pada 524 nm. Di sisi lain, Eosin Y@MOF Zr-NDC menunjukkan puncak-puncak serapan pada 300, 357, dan $524 \mathrm{~nm}$ yang berkorelasi dengan energi celah masing-masing sebesar 3,65, 3,15, dan 2,19 eV.
\end{abstract}

Kata Kunci : Metal-organic framework Zr-NDC, Eosin Y, energi celah 


\section{LATAR BELAKANG}

Metal-Organic Framework (MOF) merupakan senyawa kristalin berpori yang terbentuk dari interaksi kuat antara ion logam dan ligan. Selama satu dekade ini telah dilaporkan sekitar 20.000 MOF dengan jenis yang berbeda untuk beragam aplikasi di antaranya adalah sebagai fotokatalis (Shen et al. 2014), pengumpul cahaya (Wang et al. 2012), penyimpan gas (Zhao et al. 2013), katalis heterogen (Wang et al. 2013) dan sensor kimia (Zhang et al. 2013). Keunggulan MOF sebagai material berpori adalah permukaannya yang luas, ukuran pori dan topologi yang beragam (Wang et al. 2013).

Seperti halnya zeolit dan material berpori anorganik lainnya, pengembanan suatu partikel berukuran nano fungsional pada MOF berpotensi meningkatkan potensi MOF sebagai katalis, penyimpan gas, penyimpan cahaya dan sensor (Schroder \& Fischer 2010). Salah satu contohnya adalah pengembanan MOF dengan molekul dye (Fang et al. 2007). Dye merupakan molekul organik berwarna yang dapat mengumpulkan energi cahaya melalui gugus kromofor sehingga menghasilkan pemisahan muatan fotoinduksi. Muatan negatif (elektron) dan muatan positif (hole) yang dihasilkan dari proses pemisahan muatan tersebut kemudian digunakan untuk berbagai transformasi kimia (Wang et al. 2012).

Penelitian mengenai pengembananan dye pada metal-organic framework telah dilakukan oleh Fang et al. pada tahun 2007 yang mengembankan rhodamin 6G (Rh6G) pada JUC-48 yaitu MOF berbasis logam kadmium dan ligan 1,4-bifenildikarboksilat. Dari hasil penelitian diketahui bahwa JUC-48.Rh6G menunjukkan sifat luminesensi yang baik pada suhu 77-298 K yaitu pada $563 \mathrm{~nm}$ (Fang et al. 2007). Selain itu, Kent et al. pada tahun 2010 telah berhasil mensintesis MOF $\left\{\mathrm{M}\left[4,4^{\prime}-\left(\mathrm{HO}_{2} \mathrm{C}\right)_{2}-\mathrm{bpy}\right]_{2} \mathrm{bpy}\right\}^{2+} \mathrm{di}$ mana $\mathrm{M}=$ Ruthenium atau Osmium. Kent et al. berhasil meyelidiki proses transfer energi dari Ruthenium dan Osmium dalam aplikasinya sebagai pengumpul cahaya (Kent et al. 2010). Metal-organic framework berbasis logam zirkonium dan ligan asam 2,6-naftalendikarboksilat diketahui memiliki kestabilan fisika, kimia dan termal yang baik. Selain itu, Zr-NDC juga menunjukkan sifat luminesensi dan porositas yang baik sehingga ketika diembankan dengan molekul dye diharapkan akan meningkatkan sifat optik MOF Zr-NDC.

\section{BAHAN DAN METODE}

Pengembanan Eosin Y pada MOF Zr-NDC mengadopsi prosedur yang dilakukan oleh Fang et al. Sebanyak 0,034 
$\mathrm{ml}$ Eosin Y $10^{-4} \mathrm{M}$ dilarutkan dalam $25 \mathrm{ml}$ etanol. Kemudian dimasukkan $0,3 \quad \mathrm{~g}$ serbuk MOF Zr-NDC dan distirrer selama 12 jam pada suhu ruang dan tanpa keberadaan cahaya untuk mengoptimalkan proses pengembanan. Setelah itu, campuran disaring dan endapan dikeringkan pada suhu $100{ }^{\circ} \mathrm{C}$ (Fang et al. 2007).

Analisa PXRD dilakukan dengan menggunakan D8 Advance Bruker powder diffractometer dengan radiasi $\mathrm{Cu} \mathrm{K}_{\alpha}(\lambda=$ $0.15406 \mathrm{~nm})$. Pengukuran persen reflektan (\%R) MOF Zr-NDC dilakukan dengan cara sampel dibuat pelet dengan ketebalan $\pm 1 \mathrm{~mm}$ dan diukur menggunakan UV-vis spectrophotometer Thermo Scientific Evolution 220.

\section{HASIL DAN PEMBAHASAN}

Karakterisasi PXRD dilakukan untuk mengkonfirmasi bahwa MOF $\mathrm{Zr}$ NDC yang disintesis telah terbentuk dengan cara membandingkan difraktogram dari MOF Zr-NDC yang telah disintesis dengan difraktogram hasil olahan data kristalografi yang telah dilakukan oleh Zang et al. (Zhang et al. 2013). MOF ZrNDC hasil sintesis memiliki pola difraksi sinar-X pada $2 \theta=6,75$ dan 7,45 seperti yang ditunjukkan pada Gambar 1. Pola ini memiliki kesesuaian dengan MOF $\mathrm{Zr}$ NDC yang disintesis oleh Zhang et al. (2013) yaitu pada bidang [111] dan [200], dan Bon et al. (2013) di $2 \theta=6,37$ dan 7,36. Pola difraksi tersebut menunjukkan bahwa MOF hasil sintesis merupakan MOF Zr-NDC. Setelah diembankan dengan Eosin $\mathrm{Y}$, kristalinitas MOF ZrNDC masih cukup baik walaupun terjadi penurunan intensitas. Hal ini dapat dibuktikan dengan masih terdapatnya pola difraksi MOF Zr-NDC. Pola difraksi yang melebar diasumsikan adalah hasil dari dua pola difraksi MOF Zr-NDC di $2 \theta=6,75$ dan 7,45 .

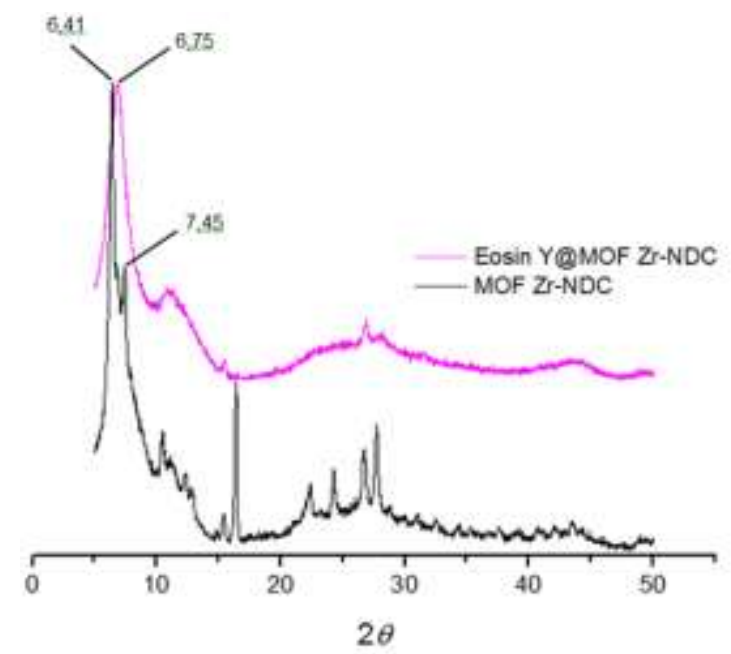

Gambar 1. Hasil analisis PXRD MOF ZrNDC.

Karakterisasi selanjutnya adalah dengan menggunakan spektrofotometer UV-vis Diffuse Reflactance Spectra untuk mengetahui serapan dan energi celah $(\mathrm{Eg})$ dari MOF Zr-NDC, Eosin Y, dan Eosin Y@MOF Zr-NDC. Spektrum reflektan difusi sampel yang diperoleh dari pengukuran dengan spektrofotometer UVvis dikonversi ke dalam fungsi Kubelka- 
Munk. Fungsi Kubelka-Munk menggunakan koefisien hamburan efektif (S) dan koefisien absorpsi efektif (K) untuk menggambarkan sifat optik dari suatu material (Murphy 2007). Tauc, Davis dan Mott memodelkan suatu persamaan untuk menghitung energi celah suatu material, yaitu:

$$
(h v \alpha)^{1 / n}=A(h v-E g)
$$

di mana $\mathrm{h}=$ kontansta Planck, $\mathrm{v}=$ frekuensi vibrasi, $\alpha=$ koefisien absorpsi, $\mathrm{Eg}=$ energi celah, dan $\mathrm{A}=$ konstanta. Nilai eksponen $\mathrm{n}$ dinotasikan sebagai transisi sampel. Umumnya, transisi sampel yang digunakan dalam eksperimen adalah transisi diperbolehkan langsung sehingga $\mathrm{n}$ $=1 / 2($ Kamat 1993).

Sumbu vertikal diganti menjadi kuantitas $\mathrm{F}(\mathrm{R} \infty)$ yang sebanding dengan koefisien absorpsi. Nilai $\alpha$ dalam persamaan Tauc disubstitusi dengan $\mathrm{F}(\mathrm{R} \infty)$. Fungsi Kubelka-Munk kemudian diplot terhadap hv. Nilai hv diletakkan pada sumbu horizontal dan nilai $(\mathrm{h} v \mathrm{~F}(\mathrm{R} \infty))^{2}$ diletakkan pada sumbu vertikal. Satuan untuk ho dalam elektron volt (eV) dan hubungannya dengan panjang gelombang adalah hv $=1239,7 / \lambda$. Setelah itu, ditarik sebuah garis singgung pada kurva. Nilai pada titik perpotongan garis singgung dengan sumbu horizontal dinyatakan sebagai energi celah (Eg) sampel.
Hasil penelitian Bhattacharjee dan Ahmaruzzaman (2015) menyatakan bahwa Eosin Y-etanol memiliki serapan di panjang gelombang cahaya tampak yaitu $524 \mathrm{~nm}$ (Bhattacharjee \& Ahmaruzzaman 2015). Serapan pada panjang gelombang yang sama juga diperoleh dari larutan Eosin Y-etanol yang diukur dengan menggunakan spektrofotometer UV-vis seperti yang ditunjukkan pada Gambar 2. Sementara itu, MOF Zr-NDC memiliki serapan di panjang gelombang $274 \mathrm{~nm}$. Hal ini menunjukkan bahwa MOF $\mathrm{Zr}$ NDC hanya dapat menyerap cahaya ultraviolet. Pengembanan Eosin Y pada MOF Zr-NDC memberikan serapan yang berada pada rentang cahaya ultraviolet dan cahaya tampak yaitu di panjang gelombang 300, 357, dan $524 \mathrm{~nm}$.

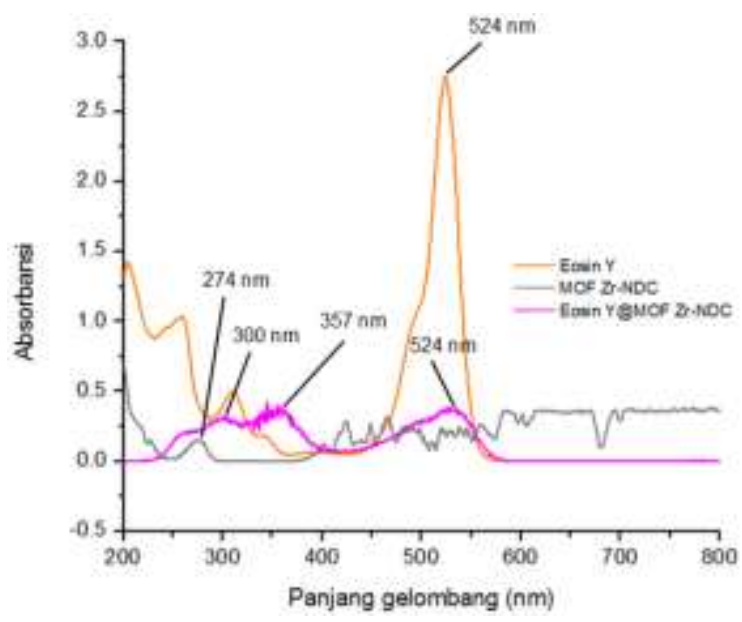

Gambar 2. Spektra serapan Eosin Y, MOF ZrNDC dan Eosin Y@MOF ZrNDC.

Gambar 3(a) menunjukkan bahwa MOF Zr-NDC memiliki energi celah 4,32 eV yang menggambarkan transisi elektron dari orbital $2 \mathrm{p}$ dari atom oksigen yang 
terisi elektron ke orbital $4 \mathrm{~d}$ dari atom zirkonium yang tidak terisi elektron (Kesuma 2015). Meskipun energi celah MOF Zr-NDC masih termasuk ke dalam

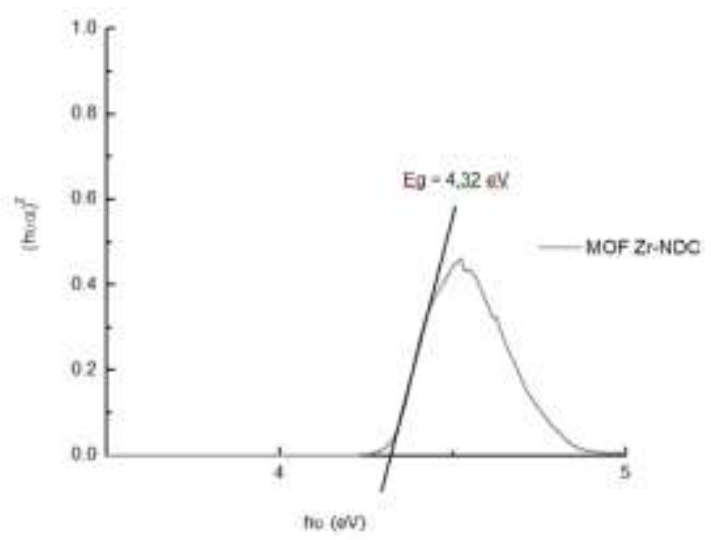

(a)

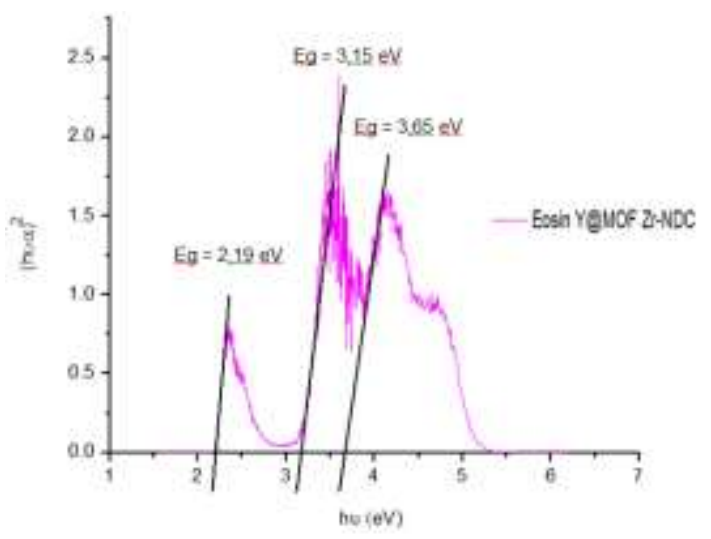

(b)

Gambar 3. Pengukuran energi celah (a) MOF Zr-NDC, (b) Eosin Y@MOF ZrNDC

rentang semikonduktor yaitu $0,5-5,0 \mathrm{eV}$ (Linsebigler et al. 1995), namun aktivitas fotokatalitik MOF Zr-NDC masih kurang baik jika dibandingkan material fotokatalis lainnya seperti $\mathrm{TiO}_{2}, \mathrm{ZnO}$, dan $\mathrm{SnO}_{2}$ dengan energi celah 3-3,8 eV (Chowdhury et al. 2015). Spektra pada Gambar 3 menunjukkan bahwa setelah diembankan dengan Eosin Y, MOF Zr-NDC memiliki tiga energi celah yaitu 2,19, 3,15, dan 3,65
eV yang berkorelasi dengan serapan 524, 357, dan $300 \mathrm{~nm}$. Ketiga energi celah berpontensi untuk reaksi fotokatalisis yang memanfaatkan cahaya ultraviolet dan cahaya tampak. Penambahan Eosin Y pada MOF Zr-NDC memunculkan localized state pada MOF Zr-NDC yaitu pada energi sebesar 3,15 eV.

Berdasarkan hasil penelitian ini dapat disimpulkan bahwa telah berhasil disintesis Eosin Y@MOF Zr-NDC dengan cara pengembanan pada suhu ruang. Hasil karakterisasi PXRD menunjukkan bahwa struktur MOF Zr-NDC dapat dipertahankan dengan penambahan Eosin Y pada MOF Zr-NDC. Karakterisasi dengan spektrofotometer UV-vis DRS menunjukkan bahwa Eosin Y@MOF ZrNDC memiliki energi celah sebesar 2,19, 3,15 , dan $3,65 \mathrm{eV}$ yang berkorelasi dengan serapan pada 524, 357, dan $300 \mathrm{~nm}$. Terdapatnya tiga energi celah ini diharapkan dapat meningkatkan kemampuan Eosin $\quad \mathrm{Y} @ \mathrm{MOF} \quad \mathrm{Zr}-\mathrm{NDC}$ sebagai fotokatalis.

\section{UCAPAN TERIMAKASIH}

Penulis mengucapkan terimakasih kepada Lembaga Penelitian dan Pengabdian Masyarakat Universitas Ma Chung atas bantuan dana dalam rangka Penelitian Dosen Pemula dengan Nomor 012/BAP/P-I/MACHUNG/LPPM-

PDP/2016 serta kepada Program Studi 
Kimia dan Ma Chung Research Center for

Photosynthetic Pigments, Universitas Ma

Chung atas penyediaan bahan dan fasilitas

laboratorium selama penelitian.

\section{DAFTAR PUSTAKA}

Bhattacharjee, A. \& Ahmaruzzaman, M., 2015. Facile synthesis of 2dimensional $\mathrm{CuO}$ nanoleaves and their degradation behavior for Eosin Y. Materials Letters, 161, pp.20-25.

Bon, V., Senkovska, I., Weiss, M. S., and Kaskel, S., 2013. Tailoring of network dimensionality and porosity adjustment in $\mathrm{Zr}$ - and Hf-based MOFs. Crystal Engineering Communications, 15, pp.9572-9577.

Chowdhury, P., Gomaa, H. \& Ray, A.K., 2015. Sacrificial hydrogen generation from aqueous triethanolamine with Eosin $\quad \mathrm{Y}$-sensitized $\mathrm{Pt} / \mathrm{TiO}_{2}$ photocatalyst in UV, visible and solar light irradiation. Chemosphere, 121, pp.54-61.

Fang, Q., Zhu, G., Jin, Z., Ji, Y., Ye, J., Xue, M., Yang, H., Wang, Y., and Qiu, S., 2007. Mesoporous metal organic framework with rare etb topology for hydrogen storage and dye assembly. Angewandte Chemie International Edition, 46, pp.66386642.

Kamat, P. V., 1993. Photochemistry on nonreactive and reactive (semiconductor) surfaces, Chemical Reviews, 93, pp.267-300.

Kent, C.A., Mehl, B.P., Ma, L., Papanikolas, J.M., Meyer, T.J., and Lin, W., 2010. Energy transfer dynamics in metal-organic frameworks. Journal of the American Chemical Society, 132, pp.1276712769.
Kesuma, R., 2015. Sintesis MOF Zirkonium-Naftalendikarboksilat

(DUT-52) Melalui Pemanasan Gelombang Mikro sebagai Fotokatalis untuk Reduksi Cr(VI), Tesis, Fakultas Matematika dan Ilmu Pengetahuan Alam, Institut Teknologi Bandung, Bandung.

Linsebigler, A.L., Lu, G., and Yates, J.T., 1995. Photocatalysis on $\mathrm{TiO}_{2}$ surfaces: Principles, mechanisms, and selected Results. Chemical Reviews, 95, pp.735-758.

Murphy, A.B., 2007. Band-gap determination from diffuse reflectance measurements of semiconductor films, and application to photoelectrochemical. Solar Energy Materials and Solar Cells, 91, pp.1326-1337.

Schröder, M (Ed.), 2010. Functional Metal Organic Framework: Gas Storage, Separation, and Catalysis, SpringerVerlag Berlin Heidelberg, Heidelberg.

Shen, L., Liang, R., Luo, M., Jing, F. and $\mathrm{Wu}, \mathrm{L} ., 22014$. Electronic effects of ligand substitution on metal-organic framework photocatalysts: the case study of UiO-66. Physical Chemistry Chemical Physics, 17, pp.117-121.

Wang, C., Liu, D. \& Lin, W., 2013. Metalorganic frameworks as a tunable platform for designing functional molecular materials. Journal of the American Chemical Society, 135, pp.13222-13234.

Wang, J.L., Wang, C. \& Lin, W., 2012. Metal-organic frameworks for light harvesting and photocatalysis. ACS Catalysis, 2, pp.2630-2640.

Zhang, W. Huang, H., Liu, D., Yang, Q., Xiao, Y., Ma, G., and Zhong, C., 
2013. A new metal-organic framework with high stability based on zirconium for sensing small molecules. Microporous and Mesoporous Materials, 171, pp.118124.

Zhao, Q., Yuan, W., Liang, J., and Li, J., 2013. Synthesis and hydrogen storage studies of metal-organic framework UiO-66. International Journal of Hydrogen Energy, 38, pp.1310413109. 